\title{
The Outlook of First Professional Medical Students: Do We Need to Guide Them? A Study from India
}

\author{
Chawla, $\mathrm{O}^{1}$., Bhattacharjee, $M^{2}$., Kansal, N.K ${ }^{3}$
}

\begin{abstract}
Objectives: The rapid expansion in the number of medical colleges in India calls for analysis of the aspirations of students who enrol into these colleges. A number of studies have been conducted on similar lines in various countries. This study is an attempt to explore the outlook of medical students in a college in Northern India.
\end{abstract}

Methods: A set of four open ended questions was given to first year medical students. The questions were related to various aspects such as, reasons for choosing a medical career, expectations from the medical college, time management and learning methods. The students' responses were grouped into a number of categories, although no predefined choices were given.

Results: The percentage distribution of responses of the students to each question was calculated. The results indicated that most students chose a career in medicine due to parental pressure, their expectations from medical colleges were mainly teacher-oriented, they had poor awareness of time management skills and they mostly used traditional learning methods.

Conclusions: The students need to be made aware about time management strategies and optimal learning methods. We suggest that medical colleges in India introduce a structured orientation program, in which these aspects are introduced to students by experts in the respective fields.

Keywords: Medical career; Parental pressure; Learning methods; Time management

\section{Introduction:}

The tremendous growth of medical education in India, especially in the private sector, is the most dominant feature of the current Indian medical education landscape (Mahal \& Mohanan, 2006).

The national regulatory body mainly focuses on infrastructure and human resources; the quality of education and outcome seem to be comlargely ignored (Sood, 2008). Although

\footnotetext{
${ }^{1}$ FAIMER Fellow, Department of Physiology

Gian Sagar Medical College and Hospital

Ram Nagar, Patiala-140601, India

${ }^{2}$ Department of Physiology

Vardhman Mahavir Medical College \& Safdarjung Hospital

New Delhi-110029, India

${ }^{3}$ Department of Dermatology and Venereology

Gian Sagar Medical College and Hospital

Ram Nagar, Patiala-140601, India

Corresponding author:

Naveen Kumar Kansal, MD

Department of Dermatology and Venereology

Gian Sagar Medical College and Hospital

Ram Nagar, Patiala-140601, India

E-mail: kansalnaveen@gmail
}

some teachers give thoughts on the quality of medical education from time to time (Anand, 2009), there are very few who have worked on aspirations of the students per se. Every year, thousands of young talented minds enrol in various medical colleges throughout India. Why do they do so? What are their expectations from the medical college and the medical education? How do they intend to manage their time? And what are their learning methods? It is worthwhile to ponder upon these questions as the answers to these seemingly benign, basic questions are bound to have a lasting impact on the medical fraternity and the society as a whole. We in our medical college, a private concern and only several years old, tried to address these questions.

\section{Methods}

First year medical (MBBS) students were selected as the study group. A set of four open ended questions was given to the students within the first week of their entry into the medical college. The questions were as follows: 
1. Why did you opt to join the Bachelor of Medicine and Bachelor of Surgery (MBBS) course (the medical course)?

2. What are your expectations from the medical college?

\section{How do you manage your time?}

4. What is your learning method?

Most studies of this kind have utilized standardized questionnaires such as the Approaches and Study Skills Inventory for Students (ASSIST) (Entwistle, 2000) or the Medical Situations Questionnaire (McManus et al., 2006). We deliberately chose not to use them, because although these tools confer uniformity and are convenient for statistical analysis and calculation of levels of significance etc., these do not give freedom of expression to the students and may not actually reach out to them. Therefore, in the process, these questionnaires may be less helpful to understand a student's point of view in a broader, more qualitative way.

It was not mandatory for the students to answer all the questions or disclose their identity. This approach was taken to ensure honest responses. Out of 100 students, 56 students had completely answered all the four questions. The responses were collected from the students and read and analyzed separately by the three investigators.

\section{Results}

A total of 56 students had answered all the four questions. Their responses were analyzed by the three investigators. It was a common observation that the responses could generally be grouped into five to seven categories, that is, the student responses were similar with respect to a particular question although no predefined choices were given. Therefore the responses were broadly grouped into 5-7 categories and the percentage of students in each group for a particular question was calculated. The responses give us a fair amount of insight about the outlook of these young medical students.

Response to question 1: Fifty percent of the students had opted for the medical profession to fulfil parental aspirations. Others joined the course as it was their aim in life, or simply because medicine is considered a noble profession with percent distribution of $16 \%$ $(n=9)$ in each group. Another $16 \%$ joined the course in order to serve society. Further $2 \%$ students stated that they joined just by chance.

Response to question 2: Fifty two percent of students had teacher-oriented expectations such as friendly and approachable teachers. Twenty percent wanted a firm infrastructure, $5 \%$ students wanted a comfortable learning environment, only $4 \%$ students were aware of teaching methods, $14 \%$ students regarded the college as the information provider and the remaining $5 \%$ had a blind faith in college.

Response to question 3: Fifty nine percent of the students followed a standard routine which fulfilled study, sleep and play. Fourteen percent students asked for guidelines in time management, $7 \%$ students did not believe in planning. Other students believed in planning and punctuality and setting a target.

Response to question 4: Twenty eight percent students used the traditional method of reading, writing and memorizing. Another $28 \%$ referred to class notes. Others consulted reference books and university question papers. Some preferred to clarify doubts in class. Only 4\% students believed in peer discussion and $1 \%$ of the students decided to plan according to medical curriculum.

\section{Discussion}

The first question has been dealt by various authors in western countries and students have reported varied motives for joining medicine such as respect for profession, indispensability and social desirability etc., (McManus et al., 2006; Gillies et al., 2009).

In the present study, $50 \%$ of the students had opted for the medical profession solely to fulfil parental aspirations. Joining any career due to parental wish and / or pressure reflects a number of facts. First and foremost is the old Indian tradition, where both parents and children strive to fulfil each other's' dreams. This is beneficial for harmony at the individual and family level. At the level of society or nation, however, it would be more productive if students decided to join the course out of personal interest or for the purpose of research, and not due to any external factor. Secondly, this also emphasizes the role of family in choosing a career and thus in a country like India where doctor-patient ratio is still abysmally low, there is a potential to educate families about careers in medicine (Amin et al., 2009). A fairly large percentage of students also chose this career out of respect for the medical profession as reported in various other studies. These observations 
suggest that the choice of this profession by the students is not purely a personal decision based on either awareness or interest in the vast field of medicine.

The second question explored the students' expectations from the medical college. The students are the major stakeholders in an educational system and it is evident that students' expectations have changed over the years. Students in this study had more of teacher-oriented and infrastructure-related expectations. The teacher characteristics preferred by students were to be friendly, approachable etc. An Australian study also reported similar student preferences (Ho \& Tani, 2007). Few students wanted a firm infrastructure and more recreational activities, although they did not define any specific requirement. Academic expectations such as library and laboratory facilities were also not apparent in their responses.

Thus students' response to the second question gave us the impression that their expectations were mostly non-academic. Probably this indicates a lack of awareness on the part of the students. We suggest that students should be counselled in this regard prior to their entry into a medical school. There should be a common platform for discussion between teachers and students to avoid a mismatch between students' expectations and teachers' training. It would seem sensible that we as educators take a more strategic approach to student expectations.

Time management is a useful skill in any profession but within medicine it has broader perspective than one can imagine. Time constraints severely affect performance of an individual. It can be argued that there is always enough time, but some people do not know how to manage or rarely, intentionally may not manage it (Sharif \& Ismail, 2010). Most of the students seem to be unaware of the importance of time management. Few of them even asked for guidelines for time management. The first year in medical school is reported to be the most stressful (Mahajan, 2010) and proper time management will certainly help students to cope up. Time management courses are mandatory in the corporate world; however it is one of the least treaded areas in medical education. Improving the prioritization and organization of study time may help to enhance a student's performance (West \& Sadoski, 2011). We feel that it is extremely important to arrange for an orientation course wherein the students can be introduced to proper time management techniques and skills by experts in the field.
The last question addressed the issue of the learning methods adopted by the students. Three main learning styles have been defined among students, namely surface learning style, strategic or achieving style and deep learning style (Shankar, 2006). The idea of a fixed or rigid learning style however has been challenged (Walsh, 2007). On similar lines, Laurillard had stated that learning styles are context- and topic-dependent and cannot be uniform or holistic (Laurillard, 1979).

It appears our students mostly adopted a surface learning style probably with an aim of passing examinations. Learning strategies such as writing and memorizing dominated in responses given by students in this study. Peer discussion which is very helpful in this professional course was reported by only 3 students. Surprisingly, none of the students reported learning with the help of internet. It is important that students are informed about the merits and demerits of e-learning as well.

\section{Conclusions}

The analysis of the medical students' responses to the set of four questions given reveals that outlook of medical students is varied. At the same time, it reveals a lack of awareness among them. In fact, one of the educator's major role in the present scenario seems to be that of a guide. Poor coping capabilities on the students' part and lack of guidance on our part will surely have a negative impact. The results have revealed the primary reason for students to join a medical college and their expectations from the institution, however at this juncture we can do little about these aspects. Nevertheless, the aspect of time management and learning methods can be taken care of up to a certain extent. "Vision 2015" for undergraduate medical education by the Medical Council of India has suggested a 2-month foundation course in the first year "to prepare students to study medicine effectively" (Medical Council of India, New Delhi, 2015). We suggest that this time could be utilized to formally train students about various learning methods and principles of optimum time management. This initial step will surely yield rich dividends.

\section{References}

Amin, Z., Tani, M., Eng, K.H., Samarasekara, D.D. \& Huak, C.Y. (2009) Motivation, study habits, and expectations of medical students in Singapore, Medical Teacher, 31, pp. 560-569.

Anand, A.C. (2009) Medical education in India: moments of pensive introspection, Tropical Gastroenterology, 30, pp. 54-58. 
Entwistle, N.J. (2000). Approaches and study skills inventory for students (ASSIST) [Online] available at http://www.tla.ed.ac.uk/et//questionnaires/ASS IST.pdf.

Gillies, R.A., Warren, P.R., Messias, E., Salazar, W.H., Wagner, P.J. \& Huff, T.A. (2009) Why a medical career and what makes a good doctor? Beliefs of incoming United States medical students, Education for Health (Abingdon), 22, pp. 331.

Ho, M.T.\&Tani, M. (2007) What medical students value from their teachers, Australian Health Review, 31, pp. 358-361.

Laurillard, D. (1979) The processes of student learning, Higher Education, 8, pp. 359-409.

Mahajan, A.S. (2010) Stress in medical education: a global issue or much ado about nothing specific? South-East Asian Journal of Medical Education, 4, pp. 9-13.

Mahal, A. \& Mohanan, M. (2006) Growth of private medical education in India, Medical Education, 40, pp. 1009-1011.

McManus, I.C., Livingston, G. \& Katona, C. (2006). The attractions of medicine: the generic motivations of medical school applicants in relation to demography, personality and achievement, BMC Medical Education, 6, pp. 11.

Medical Council of India, New Delhi: Vision (2015) [Online] available at:http://mciindia.org /tools/announcement/MCl_booklet.pdf.

Shankar, P.R., Dubey, A.K., Binu, V.S., Subish, P. \& Deshpande, V.Y. (2006) Learning styles of preclinical students in a medical college in western Nepal, Kathmandu University Medical Journal, 4, pp. 390-395.

Sharif, A.M.\& Ismail, O.H. (2010) Managing time: a study among Arab Open University tutors in Kuwait ranch. College Teacher Methods \& Styles Journal, 6, pp. 13-20.

Sood, R. (2008). Medical education in India. Medical Teacher, 30, pp. 585-591.

Walsh, K. (2007). Learning styles: do they really exist? Medical Education, 41, pp. 618-620.

West, C. \& Sadoski, M. (2011). Do study strategies predict academic performance in medical school? Medical Education, 45, pp. 696-703. 